\title{
EL MAPUDUNGÚN EN SANTIAGO DE CHILE: VITALIDAD Y REPRESENTACIONES SOCIALES EN LOS MAPUCHES URBANOS*
}

\author{
MAPUDUNGUN IN SANTIAGO DE CHILE: VITALITY AND \\ SOCIAL REPRESENTATION AMONG URBAN MAPUCHE PEOPLE
}

\author{
CRISTIÁN LAGOS F. \\ Universidad de Chile. Santiago, Chile \\ crlagos@uchile.cl
}

\section{RESUMEN}

El objetivo de la investigación fue estudiar la situación del mapudugún en la ciudad de Santiago de Chile, en cuanto a su vitalidad lingüística, descrita a partir de parámetros como la competencia -discursiva, léxica, escrita y comunicativa- que los hablantes tienen en ella, así como también considerando los espacios funcionales en los que se verificaba su uso. Además, se intentó dar cuenta de las representaciones sociales que tienen respecto de su lengua. Se adoptó una perspectiva metodológica mixta, aplicando una encuesta y entrevistas semiestructuradas a mapuches urbanos, observación participante en agrupaciones indígenas y uso de fuentes secundarias de información. Los resultados obtenidos muestran un desplazamiento funcional a favor del castellano, con la pérdida paulatina de espacios en los que predominaba o le eran exclusivos. Sin embargo, a nivel de las actitudes y representaciones sociales se pudo constatar la existencia de un sentimiento de apego y revalorización hacia el mapudungún, que rescata su valor simbólico identitario antes que lingüístico, lo que es expresión de procesos mayores de reetnificación en la ciudad en torno a lo mapuche. Por otra parte, a nivel de los mecanismos de reproducción de la lengua, emergió con claridad la progresiva retirada de los espacios tradicionales y naturales para tal función, como la comunidad y el hogar, a la vez que otros emergen con fuerza: la escuela y los talleres, característicos de una racionalidad cultural ajena, no nativa.

Palabras clave: Etnolingüística, mapudungún, vitalidad lingüística, representaciones sociales.

* En el presente artículo se muestran los resultados finales del proyecto financiado por la Vicerrectoría de Investigación y Desarrollo de la Universidad de Chile "Competencia, vitalidad y lealtad lingüística del mapudungún en Santiago de Chile” (SOC 08/07-2), desarrollado en 2009 y 2010. Mañumtum (agradecimientos): a los peñi y lamngen que colaboraron con el estudio, Tania Beroiza, Felipe Hasler, don Héctor Mariano, Daniela Molina, Cristián Oyarzo y Paulina Slaughter. Sin ellos éste no se habría realizado. 


\section{ABSTRACT}

The aim of this piece of research was to study the linguistic vitality of Mapudungun in the city of Santiago de Chile, taking into account for its description the (discursive, lexical, writing and communicative) competence that speakers of such language possess, as well as those functional spaces in which its use was observed. Additionally, this study attempts to account for the social representations speakers have about their language. To this end, a quantitative-qualitative methodological perspective was adopted, which involved the application of a survey and the carrying out of semistructured interviews to urban mapuche, participant observation in urban indigenous associations and the access to secondary sources of information.

Keywords: Ethnolinguistics, Mapudungún, linguistics vitality, social representations.

Recibido: 19.12.2011. Aceptado: 11.04.2012.

\section{INTRODUCCIÓN}

Teniendo como temática central la descripción de la situación de la lengua mapuche en Santiago de Chile, nos proponemos: a) caracterizar el mapudungún
en términos de su vitalidad lingüística, en cuanto a su grado de uso y espacios funcionales; b) identificar el grado de competencia en mapudungún de los mapuches en Santiago, tanto efectiva como declarada, y tanto en el ámbito léxico y como en el de la producción discursiva; c) describir la representación social que ellos han construido respecto de su lengua; y d) aproximarse al papel que el mapudungún juega en la construcción de una nueva identidad mapuche urbana.

Para este estudio de nivel descriptivo utilizamos una metodología de recolección y análisis de tipo mixta, cualitativa y cuantitativa. La estrategia cualitativa consistió en recoger información respecto de los discursos a través de los cuales los mapuches urbanos construyen su identidad como tales y las representaciones sociales en torno a su lengua nativa. Se aplicó, de esta forma, una entrevista semiestructurada a 16 mapuches urbanos ( 8 mujeres y 8 hombres). A estas fuentes de información primaria se sumó el acceso a fuentes secundarias, constituidas por discursos (16 textos) sobre el mapudungún presentes en documentos que transmiten la visión oficialista sobre el tema, así como también a otros documentos (12 textos) representativos de la visión de las elites intelectuales mapuches al respecto. Además, a través de una metodología etnográfica, se realizó observación participante en distintos espacios en los que el mapudungún es utilizado en la ciudad (agrupaciones, servicios públicos, talleres de lengua). La dimensión cuantitativa correspondió a la aplicación de una encuesta a mapuches urbanos, entre mayo y octubre de 2009, a una muestra construida en base a un muestreo no probabi- 
lístico por cuotas ( $\mathrm{n}$ alcanzado = 232), en comunas de la Provincia de Santiago, con un $\mathrm{p}$ value de 0,05 y un error estimado de $5 \%$. Se asumieron los valores de $\mathrm{p}$ 0,36 y q 0,64, considerando como referencia un estudio previo del CEP (2006). Los datos obtenidos se analizaron con el programa SPSS 10.0, en términos de estadística descriptiva.

\section{LA VITALIDAD EN SU DIMENSIÓN CUANTITATIVA}

\subsection{Competencia en mapudungún}

Nuestra primera línea de base, para evaluar la competencia lingüística de los mapuches urbanos en su lengua originaria, surgió a partir de indagar en su percepción de cuánto creían conocerla. Nuestro hallazgo fue que los niveles declarados de competencia resultaron ser bastante bajos: en una escala de 1 a 5 , donde 1 corresponde ningún conocimiento y 5 el máximo, la mayoría de los encuestados, casi un 70\%, se autocalificaron en un nivel 1 ó 2 . Como contrapartida, sólo poco más de un $17 \%$ se ubicó en los tramos más altos de competencia, quedando el nivel máximo sólo para un 6,5\%. Ahora bien, cuando se les pidió poner en práctica aquella competencia declarada en una producción discursiva simple (secuencia de imágenes de niño cepillándose los dientes), la impresión obtenida anteriormente se vio confirmada y amplificada. Ello, pues el $86 \%$ de los entrevistados fue incapaz de describir algún componente básico de aquélla. Luego, si nos centramos solamente en aquellos encuestados que lograron la descripción total o parcial de la secuencia, sólo un tercio de ellos logró un nivel de competencia calificado como alto (basándonos en Hasler, Lagos, Mariano, Molina y Oyarzo, 2009, y Gunderman, Canihuán, Clavería y Faúndez, 2009). En síntesis, observamos la mermada condición en la que se encuentra uno de los dos componentes básicos para asegurar la vitalidad de la lengua (siendo el otro la existencia, generación y validación de espacios funcionales): la competencia en la lengua. Aspecto que, como veremos más adelante, adquirirá importancia al analizar los discursos de los mapuches sobre su lengua y cultura. Si comparamos esto con los estudios previos (Lagos, 2006; CEP, 2006; Gunderman et al., 2009) se confirma esta radiografía respecto de la baja competencia declarada y/o efectiva en mapudungún, una tendencia que se venía proyectando desde las primeras investigaciones en el tema (Salas, 1985).

Entre las variables que pueden estar incidiendo en este panorama, la "edad" del encuestado, antes determinante en la relación campo-ciudad (según estudios previos, como Hernández, 1983; Lagos, 2006; Gunderman et al., 2009, en donde se evidenciaba una relación proporcional directa con el nivel de competencia, esto es, a mayor edad mayor competencia), aquí en la ciudad parece comportarse de modo diferente. Vemos que en el tramo más alto de edad (65 o más años) nadie 
de los que declaró ser competente alcanza un nivel de competencia alta. De hecho, es en los tramos de 18 a 24 y de 45 a 54 años donde encontramos la mayor proporción de aquellos que se pueden calificar como de "alta competencia". Lo anterior, creemos, se puede explicar porque, como lo señalaron algunos de los entrevistados, a) la inexistencia de espacios funcionales en el entorno urbano en los que practicar la lengua -a diferencia de lo que puede ocurrir en el ámbito rural, en donde en la vida familiar o local sí los hay- ha hecho que muchos hayan olvidado lo que habían aprendido antes de migrar a la ciudad; b) además, es el acceso a valores propios de la racionalidad occidental, la educación y el orgullo por la propia condición étnica, lo que puede hacer entender que muchos jóvenes hayan optado por aprender lengua ya sea de forma autodidacta o a través de canales semiformales, como lo son los talleres de lengua que se imparten en algunas comunas de la ciudad con alta proporción indígena. De esta manera, se posiciona a la escuela y a los talleres como instancia nueva en la que se reproduce la lengua, agencias que son accesibles a las nuevas generaciones, predominantemente. La idea anterior se refuerza cuando correlacionamos la competencia en la lengua y el nivel de instrucción de los encuestados: encontramos que aquéllos con competencia baja o media se concentran en los tramos con menos estudios (no asistió al colegio o enseñanza básica incompleta, lo que coincide, a su vez, con los segmentos que corresponden a una primera generación de llegados a la ciudad desde el ámbito rural del sur del país). A su vez, es en quienes han completado su instrucción en la escuela (cuarto medio completo) en donde encontramos el segmento que predomina en la posesión de una alta competencia en la lengua.

En segundo lugar pasaremos a revisar algunos aspectos de la competencia de los encuestados en el nivel léxico. Este ítem se ponderó a través de la administración de una lista de léxico fundamental en la que debían responder “¡cómo se dice en mapuche...?, aspecto que también nos permitió profundizar en la dimensión gráfica de esta lengua. En general, se observó un muy pobre conocimiento de vocabulario fundamental, en ítemes tan elementales como los términos para hermanolhermana, muy comunes e identificatorios del modo de tratamiento de los mapuches (más del $60 \%$ o desconoce o responde incorrectamente), o con una de las palabras mapuches más recurrentes, tierra (más del 50\% no la conoce o lo hace de modo incorrecto). Además, en un dato que da cuenta de los niveles de competencia comunicativa (Hymes, 1971), la mayoría eran incapaces de distinguir el tratamiento, según la variable de género, que se debe dar al término hermana/ hermano (de acuerdo al ad mapu, sólo los hombres pueden tratar al hermano de peñi, mientras las mujeres deben usar sólo el término lamngen tanto para hermano como hermana). Sólo de aquellos que fueron capaces de traducir el ítem al mapudungún, casi el $80 \%$ no reconocía su uso diferencial según género. Esto último se constituye en otro indicador más de su baja competencia, ya no sólo idiomática, sino que comunicativa y cultural. 
La evaluación de la competencia léxica, a su vez, permitió observar el empleo de un sistema gráfico para expresarse. Para cumplir con esta función, distintos grupos mapuches han propuesto su modelo de grafemario o alfabeto como el más adecuado (Mariano, 2009), sin aún llegar a un acuerdo. En base a las características de cada grafemario se discriminó en el corpus obtenido cuál era el predominante. Los resultados fueron más que esclarecedores (considerando sólo a aquellos que escribieron el nombre en mapuche para la palabra en castellano), pues observamos que lo más recurrente era que la gran mayoría, casi un 75\%, no utilizaba ningún grafemario conocido, predominando más bien la anarquía en la escritura. Dentro de los que sí utilizaron un grafemario, el más usado fue el "alfabeto unificado", aunque nunca en estricto rigor (nadie utilizaba, por ejemplo, los diacríticos en "t." o "l.", como lo indica ese sistema). El dato resulta relevante toda vez que las grandes discusiones que las elites intelectuales del mundo mapuche han generado en torno a su lengua y su futuro se han consumido en buscar un alfabeto unitario para ella, asumiendo esto como su principal problema (lo que es confirmado también en nuestro análisis cualitativo más adelante). Lo que los datos demuestran es que tal vez lo sea para las elites, pero no es el principal problema para los hablantes comunes y corrientes: para ellos el problema es no conocer su lengua, ni contar con espacios sociales legitimados para utilizarla. En otras palabras, ningún sentido ha tenido proponer " $\mathrm{x}$ " número de alfabetos y defender cada uno como la mejor opción, cuando en realidad los hechos demuestran que lo que urge es la promoción social de la lengua y su difusión como instrumento de comunicación legítimo en una sociedad poco receptiva a la realidad indígena. Así, al menos en este caso, parece claro que hace falta poner el énfasis en una planificación de estatus antes que de corpus (Chiodi y Loncón, 1995), es decir, desarrollar acciones tendientes a dotar de prestigio y utilidad social al mapudungún.

\subsection{Espacios de vitalidad}

Al situar nuestra atención en los espacios funcionales del mapudungún en la urbe, los estudios previos (Lagos, 2006; Salas, 1985; Hernández y Ramos, 1978, 1979; Gunderman et al., 2009) señalaban que uno de los espacios que se mantenían más firmemente como agencias de producción y reproducción de la lengua era el de las ceremonias religiosas y tradicionales mapuche, junto con el de la interacción familiar. Los primeros estudios sobre el tema (Hernández y Ramos, 1978, 1979; Hernández 1983) los mostraban como uno de los bastiones en los que se generaba reproducción de la lengua. Nuestro registro mostraría que esta tendencia ha cambiado en la ciudad hoy. En primer término, como era de esperar en una ciudad como Santiago, que en el hogar, en la vida cotidiana, el uso del español se reconoce casi universalmente, con exclusión del uso de la lengua mapuche, la que es reconocida como principal sólo por una mínima proporción de encuestados. Lo mismo 
se verifica también en ámbitos cotidianos, como el uso de la lengua mapuche en la interacción con la pareja o familia cercana, el que fue calificado en una escala de 1 a 5 , siendo 1 un grado nulo y 5 el máximo grado de uso (casi el $90 \%$ se sitúa en los niveles 1 ó 2). Este retroceso funcional en los espacios familiares se corresponde con otra situación, en el plano de las agencias en las que se reproduce socialmente la lengua y la cultura. Tradicionalmente, y como toda lengua oral, la agencia de socialización por excelencia donde el niño la aprendía era en las interacciones cotidianas de su familia. Sin embargo, ahora y en la ciudad, esa característica ha comenzado un proceso de retroceso, emergiendo nuevos espacios de socialización. Si bien la mayoría de los encuestados (60\%) sigue reconociendo a la familia -y el hogar-como el principal espacio en el que se reproduce el saber lingüístico, cuando cruzamos este dato con la generación a la que pertenece encontramos fundamento a lo señalado: la familia retrocede en pos de otras agencias, como la escuela, en tanto observamos cómo, a medida que los sujetos han nacido en la ciudad, o son hijos de mapuches nacidos allí, el rol de la familia como agente de transmisión de la lengua va disminuyendo hasta igualarse al aprendizaje autónomo, en sujetos pertenecientes a una cuarta generación de llegados a Santiago.

El otro espacio tradicional de uso del mapudungún, destacado por estudios previos, lo constituían las ceremonias religiosas y tradicionales. Como era de esperarse, si bien éste mantiene niveles importantes de uso, también se observa mermado, siendo minoritario cuando lo comparamos con el uso del castellano en tales instancias ( $58,4 \%$ señala usar castellano). En este ámbito social, si bien la merma no parece tan significativa, resulta de todas maneras relevante en tanto era un espacio de uso exclusivo del mapudungún, y lo es aún en el sur del país, en donde ceremonias como el we tripantu o el nguillatún son exclusivamente desarrolladas en la lengua nativa. Ahora, ¿qué ocurre cuando observamos el uso del mapudungún en espacios que son exclusivos de la lengua oficial, como ocurre en la interacción con autoridades gubernamentales o locales y servicios públicos? Como era de esperar, y no obstante existen numerosas iniciativas para visibilizar la lengua mapuche, sobre todo en las comunas de mayor población de este origen, el mapudungún aparece desplazado a favor del castellano. El marginal porcentaje que señala usar el mapudungún (sólo un 10\%) en servicios públicos se refiere al uso de señalética en lengua nativa en muchos servicios estatales y comunales, mas no a la existencia de interlocutores que les hablen en su lengua nativa, ni a la existencia de formularios impresos en ambas lenguas. Esta asimetría en los espacios sociales exclusivos para el castellano se ve reflejada también, por ejemplo, al momento de buscar empleo. Se les preguntó a los encuestados respecto de cuánto creían que les servía conocer su lengua para encontrar un empleo, donde es claro que el mapudungún no puede competir con el castellano, pues poco más del 15\% presenta niveles de acuerdo. En síntesis, apreciamos que la lengua mapuche ve cada vez más limitados sus 
espacios de vitalidad en la ciudad, lo que es perfectamente funcional - ¿causa o efecto, o ambas cosas a la vez, en una relación sinérgica?- con los bajos niveles de competencia declarada y efectiva de los mapuches urbanos de Santiago de Chile, tanto a nivel discursivo como a nivel léxico.

Debemos consignar, sin embargo, la existencia de otros espacios de uso del mapudungún: espacios públicos, generalmente periféricos y asociados a estratos socioeconómicos bajos y medios-bajos. Este solo dato muestra que en Chile (así como en buena parte de Latinoamérica) se verifica la asociación entre ser indígena y ser pobre o marginado socialmente. Uno de los espacios más frecuentes lo constituyen los centros de salud. La lengua se usa en hospitales y consultorios en donde se atiende población de origen indígena o en donde trabaja un contingente importante de tal origen (el Hospital San Borja Arriarán, que atiende a la población del sector centro y sur de la capital, es un caso ejemplar). Sin embargo, este uso se restringe a traducir la señalética del lugar (sus distintos sectores arquitectónicos y servicios) al mapudungún. Más allá del rol social que en este caso está cumpliendo la lengua, resulta muy interesante la labor de quienes se han encargado de realizar estas indicaciones, pues han creado una serie de neologismos que intelectualizan al mapudungún y hacen viable su existencia en la ciudad, refiriéndose a realidades que no están presentes en la vida tradicional mapuche rural. Con estas iniciativas, más allá del grado de competencia efectiva y de su uso en contextos sociales relevantes en la ciudad, encontramos grupos de mapuches (en iniciativas dispersas aún) que están preparando a la lengua para cumplir nuevas funciones, elemento central para proyectarla hacia el futuro, en una suerte de "planificación lingüística" espontánea, pero aún sin articulación. Aspecto que entrega un dato relevante al momento de discutir con planteamientos apocalípticos que predecían o predicen que la lengua mapuche va a desaparecer (Salas, 1985). Otro espacio de uso similar es el ferrocarril metropolitano (el "Metro" de Santiago), en donde encontramos, en una de sus estaciones, los "Derechos del Niño" traducidos al castellano y al mapuche, constituyendo otra fuente de intelectualización del mapudungún. Del mismo modo, un céntrico café lleva el nombre de Eñum domo, literalmente "la mujer caliente" (en rigor, üñum domo, una muestra más de la anarquía gráfica que describíamos para la lengua mapuche), apelativo en la línea del local, que busca atraer al público masculino. Sin embargo, aparte del nombre, nada más en el local evoca a la cultura mapuche: no hay ningún sentido cultural en él, más allá de llamar la atención por lo exótico. Otros espacios de reproducción lo constituyen diversos periódicos en Internet que divulgan la temática mapuche, pero, y he ahí lo interesante, lo hacen en castellano (lo que reafirma nuestra idea fuerza de la ecuación perfecta entre falta de vitalidad $=$ falta de competencia $=$ falta de espacios funcionales), tal es el caso del periódico electrónico Azkintuwe. En Facebook, así mismo, también circula el mapudungún, tal vez con algo más de énfasis en la fun- 
ción comunicativa, pero predominando finalmente la identitaria en el uso de la lengua. Finalmente, otro espacio de vitalidad lo constituyen los talleres de lengua mapuche en la ciudad, nuevas agencias, algunas con más o menos base académica, que permiten que circule el mapudungún. Una experiencia de éstas, el taller de lengua mapuche que es desarrollado en la Facultad de Filosofía y Humanidades de la Universidad de Chile, ha logrado generar un libro de enseñanza de la lengua (Mariano, 2009), materialidad donde no sólo se plasma una forma vital de la lengua en los espacios urbanos actuales, sino que también es otra área de innovación y de creación de neologismos que tienden a intelectualizar al mapudungún y adaptarlo a los nuevos contextos en los que se desenvuelve.

\subsection{Rol de las estructuras de transición}

En nuestro anterior estudio (Lagos, 2006), y siguiendo lo señalado por Munizaga (1961), encontramos que las estructuras de transición (agrupaciones mapuches urbanas), que disminuyen el impacto cultural que implica llegar a una cultura dominante al momento de migrar desde el campo a la ciudad, para el caso de la población mapuche, cumplían una función protectora en lo que se refiere a la conservación y uso de la lengua. Actualmente, han evolucionado hacia instancias más formales (contando con personalidad jurídica), y su rol protector en el proceso de integración se ha desplazado a uno que se puede catalogar más bien como promotor de la particularidad étnica o nichos de conservación de la misma. Al respecto, en nuestro registro, no obstante encontrar que la participación en organizaciones mapuches urbanas no era algo general (sólo un 22\%, característica entendible en el contexto urbano, en el que las obligaciones del trabajo y estudio hacen postergar estos aspectos más simbólicos a lugares más marginales), al correlacionar esa participación con el grado de competencia de los encuestados, se observó una relación estrecha entre ambas situaciones, en la medida que en las agrupaciones, ya sea con un fin meramente identitario o comunicativo, la lengua circula y se refuerza su importancia en la esencia de ser mapuche en la ciudad. Así, de aquellos que señalan tener el nivel máximo de competencia en la lengua, todos participan en agrupaciones mapuches urbanas. Adicionalmente, podemos ir más allá de estos datos para entender cuáles son los nuevos roles que pueden estar cumpliendo las estructuras de transición, sobre todo en relación con la lengua mapuche. Recordemos que la definición clásica de Munizaga (1961) de estas entidades, en tanto puente cultural entre dos visiones de mundo, se refería a ellas como mecanismos de inserción de la cultura mapuche rural en el entorno urbano. Eso, en un contexto societal local y global propio de la década de 1960. Actualmente, sin embargo, siguiendo lo señalado por Molina, Hasler, Lagos, Mariano y Oyarzo (2009) y Oyarzo, Hasler, Lagos, Mariano y Molina (2010), el concepto no se observa de la misma 
forma, pues el problema ya no se origina en el choque de culturas producido por el abandono físico del lugar de origen (cabe recordar que la mayoría de nuestros encuestados pertenecen a una tercera generación de mapuches llegados a Santiago, es decir, han nacido aquí). El asunto radica, más bien, en que el sujeto se reconoce y siente pertenencia a un grupo, lo que conlleva la búsqueda de un contexto que propicie tal reconocimiento, y es ahí donde cumplen un rol las estructuras de transición. Esta redefinición lleva el análisis más allá: si observamos la relación entre edad y participación, encontramos que mientras los más jóvenes no tienden a participar activamente en agrupaciones, las personas de edad más avanzada sí lo hacen. Sin embargo, el nivel de competencia efectiva de los encuestados evidencia que existe un alto porcentaje de hablantes competentes entre los 18 y 24 años que no participan de agrupación alguna. Ello señala de que estas agrupaciones estarían debilitándose como lugar-exclusivo, preponderante- de aprendizaje, promoción y reproducción de la lengua (contrastando con la situación que Munizaga constataba en la década de los 60), fenómeno que amerita ser explicado en futuras investigaciones. De esta manera, entre los que tienen una competencia alta hay un alto porcentaje que sí participan en agrupaciones, pero el participar no es el único factor que explica que tengan una alta competencia: ahí aparecen otras agencias, como la escuela y los talleres.

\section{REPRESENTACIONES SOCIALES ACERCA DEL MAPUDUNGÚN}

\subsection{La información cuantitativa}

Se le pidió a los encuestados señalar su opinión, en una escala de menor a mayor acuerdo, frente a la afirmación "Para ser un verdadero mapuche hay que hablar lengua mapuche". Los resultados muestran que la representación social dentro del imaginario indígena urbano es que la lengua sí define el ser mapuche (casi un $60 \%$ se adscribe a esa idea), lo que tiene relación con la realidad mapuche urbana. Mientras en los sectores rurales tradicionales un elemento nuclear en la definición de lo mapuche es la "tierra", ésta deja su lugar simbólico en el entorno urbano, pues, por lo general, al llegar a la ciudad el migrante y su descendencia pasará a formar parte de una masa asalariada, sin tierra, por lo que un elemento central, entre otros que más adelante revisaremos, del que echarán mano para sentirse "mapuches" será su lengua nativa. Sin embargo, esta construcción de lo mapuche en torno a su lengua no tiene ningún anclaje en el conocimiento efectivo que tengan de ella o el uso real que hagan en su cotidiano (cerca del 75\% reconoce que "se puede ser mapuche sin necesariamente saber mapudungún"). Del mismo modo, aun dentro del grupo que señala ocupar menos la lengua nativa encontramos una 
importante proporción (casi el 50\%) que se manifiesta muy de acuerdo con la afirmación planteada. Esto es un elemento nuclear que podría hacer entender por qué la supervivencia de la lengua puede estar, en cierta medida, asegurada, aun cuando, tal como lo veíamos antes, su vitalidad sea baja, constituyendo una semilla que sembrar para futuras iniciativas de revitalización y promoción social del mapudungún.

Adicionalmente, este rol de la lengua en la definición de la "esencia" mapuche en la urbe se ve reafirmado cuando se pregunta respecto de si sus dirigentes deberían conocer y hablar la lengua: la gran mayoría (cerca del 80\%) está totalmente de acuerdo con esto. Los elementos anteriormente señalados muestran, a su vez, cómo la representación social sobre el mapudungún sirve como un código para el intercambio social, toda vez que, según observamos en nuestra interacción en algunas agrupaciones mapuches urbanas (Comisión Lingüística Mapuche Metropolitana, Liga Cultural Kolo Kolo, entre otras), la lengua resulta en un "filtro" que permite ubicar a los sujetos participantes dentro de redes de roles y estatus en la agrupación, al modo de desestimar el aporte u opinión de algún integrante sólo porque "no es hablante de lengua" o categorizar como "importantes" o "personas que dicen cosas interesantes" a aquellos que sí son hablantes. A su vez, quienes no son hablantes en la agrupación encuentran en esta herramienta de movilidad social dentro del grupo un acicate para aprender más y mejor la lengua. Esto se ve refrendado en los datos de la encuesta también, en donde: a) poco más del $70 \%$ muestra una orientación positiva hacia la idea de que "saber la lengua permite que lo acepten más sus pares", y b) más del $73 \%$ se orienta positivamente hacia la afirmación de que "ser hablante de mapudungún ha sido una ventaja para él/ella". Respecto del papel que juega la lengua mapuche en las problemáticas políticas que son parte del discurso de las distintas comunidades a nivel del país, las reivindicaciones sobre la lengua versus otras que se dan en las zonas rurales tradicionales aparecen en un lugar de importancia. Ello se deduce del hecho de que para una mayoría (52\%) la lengua mapuche (su promoción, su uso, reconocimiento y posibilidades para aprenderla) es la necesidad más importante de su pueblo, mientras que un 20\% no lo cree así, asumiendo los restantes una postura neutra frente a la afirmación. Por su parte, para un $42 \%$ es el Estado el que aparece como el principal responsable de estas reivindicaciones, lo que es bastante consistente con el rol que le otorga la abrumadora mayoría a la escuela como la agencia en la cual se aprenda la lengua. Recordemos que ya antes habíamos dado cuenta del creciente retroceso que otras agencias tradicionales demostraban tener en cuanto a reproductoras del saber lingüístico tradicional (la familia y las agrupaciones indígenas urbanas), lo que devela una población mapuche urbana, con un nivel de instrucción formal adecuada, que ha incorporado las pautas de la racionalidad occidental y que las aplica a la representación social de su lengua nativa, y sobre ella proyecta las posibles soluciones tanto a su falta de vitalidad lingüística como a los déficits en su aprendizaje. 


\subsection{La información cualitativa}

\subsubsection{La visión desde la matriz oficialista}

Basándonos en el análisis de una serie de documentos que reflejan la conceptualización de la situación de los mapuches y su lengua desde la óptica del discurso conservador, representativo de la manera de afrontar el tema por parte de las actuales autoridades del país (Serie "Documentos públicos" del Instituto Libertad y Desarrollo No 854 a 967), hallamos una serie de claves que permiten entender por qué para el discurso oficial temas como la lengua nativa y su retroceso funcional no son un problema prioritario a resolver, o, más aún, no son un problema. La no visibilización de la lengua mapuche $-\mathrm{y}$ su promoción social- como un tema importante guarda una estrecha relación con la tendencia general a des-etnificar la problemática mapuche (esto es, dejar de ver a esta comunidad y sus problemáticas, incluida la lingüística, como derivadas de su condición de indígenas, a raíz de un proceso histórico particular y relaciones sociales asimétricas con la sociedad chilena), al centrar sus problemas en solo uno, y que corresponde a uno propio de la población general, no necesariamente indígena: la marginalidad, pobreza e indigencia, y falta de oportunidades laborales y educacionales, fundamentalmente. Con esto no pretendemos señalar que tales problemas no existan para los mapuches del país y de Santiago de Chile, sino destacar la necesidad de que sólo situándolos en la perspectiva de sus procesos históricos particulares es posible verlos como el resultado de su condición indígena, clave para su real solución. Toda vez que las autoridades los conceptualizan fuera de su condición de etnia originaria, la solución a sus problemas pareciera emerger con claridad: hacerlos sujetos de mercado (la verdadera carta de ciudadanía actual), a través de la capacitación, implementación de mejores tecnologías para la explotación de sus tierras y el acceso al crédito. Así lo señala uno de los ministros de Gobierno, para quien “... las políticas públicas debieran enfocarse primeramente a aumentar la cobertura y calidad de la educación en las comunidades. Asimismo, se requiere invertir en infraestructura a través de la construcción de caminos y escuelas; además eliminar las trabas al derecho de propiedad, facilitando el acceso a las redes de integración comercial; entregar capacitación en materia agrícola y uso de suelos, etcétera" (Larroulet, 2009, cursivas son nuestras). Observamos, por tanto, que la base étnica del problema mapuche y de sus distintas dimensiones (incluyendo, claro, su lengua) es algo ausente, invisible. El Instituto Libertad y Desarrollo (ILD) continúa por la misma senda, des-etnificar el tema, al señalar que: “... tanto la inversión en capital humano como el empleo, son factores preponderantes en el combate de la pobreza, y en esa dirección deben ir los esfuerzos por procurar el mayor bienestar de la población indígena..." (ILD, 11 de enero de 2002: 1). En la misma línea está el aporte de la senadora Enna von Baer (ex ministra de Gobierno), quien remarca que “... se insiste en la necesidad 
de focalizar los subsidios del Estado a la Educación, vivienda e infraestructura para ayudar a las comunidades a salir de la extrema pobreza" (ILD, 2002: 2). Más adelante, en su artículo observamos cómo su discurso se acerca al ideario evolucionista decimonónico, al señalar que la solución al problema mapuche pasa por "... familiarizar a los mapuches con la democracia y propiciar su participación en ella..." (Ibid: 21), en otras palabras, así lo interpretamos, entregarles valores modernos a ellos, los "primitivos". Además, señala que dar la oportunidad de salir de la pobreza a los indígenas pasa por integrarlos al mercado, destacando su ventaja: “... no tiene que significar necesariamente la pérdida de su cultura, sino más bien su evolución. Los mapuches tendrán que integrar ...el progreso a su cultura" (Ibid.: 22, cursivas nuestras). Su apuesta, apunta a dar la libertad a los mapuches de elegir el modo de vida que desean tener y no imponérselos desde un punto de vista del "deber ser", que, como veremos adelante, es lo que argumentan muchos intelectuales mapuches respecto del derecho y obligación de los indígenas urbanos para recuperar su lengua. Aquí se mezcla, claro, la ideología neoliberal con una clara conciencia de que el mapuche urbano, permeado por tales estructuras de pensamiento, ciertamente ha asumido esa racionalidad.

Sumado a la tendencia a la des-etnificación de su problemática y de su solución por medio de la maximización de la relación costo-efectividad (en la entrega de tierras, la transferencia tecnológica, la lucha contra la pobreza, etc.) se encuentra otra arista discursiva, la criminalización del tema, donde el énfasis está puesto en tematizar a los mapuches como "problema", asociado fuertemente a los hechos de violencia que se observan en la Araucanía, vinculados a la reivindicación territorial histórica de este grupo. De esta manera, los mapuches existen de tres modos discursivos, a saber: a) como terroristas, b) como indigentes/ pobres, o c) como sujetos de mercado (situación esta que define la solución a sus problemas). En ninguna de estas categorías aparecen como indígenas, parte de un grupo étnico con una historia, lengua y cultura particulares. Eso pareciera ser invisible. Sin embargo, debe reconocerse que los pasados gobiernos de centro izquierda tienen responsabilidad de que el debate se haya situado allí: su lógica, con ciertos matices, apuntaba hacia una dirección similar, una política indígena asistencialista centrada en el reparto de tierras y subsidios.

\subsubsection{La visión de las élites intelectuales mapuches}

Nuestra experiencia participando en organizaciones indígenas dedicadas a la lengua, en sus eventos y reuniones periódicas, además de la revisión de la producción escrita respecto del mapudungún desde la intelectualidad mapuche (en periódicos como Zalpikan y documentos de CONADI), pone en evidencia que uno de los tópicos más recurrentes en su discurso ha sido y es cómo dar el paso desde la oralidad a la escritura (CONADI, 2005) y dotar de un grafemario unificado a la lengua 
(Zalpikan, No 6, junio 2010). La anarquía encontrada en la producción escrita de los sujetos que encuestamos muestra el impacto menor de las discusiones en torno al tema generadas por las elites intelectuales, juicio que no es una negación de la necesidad de estandarizar la expresión escrita de una lengua originariamente ágrafa, sino que busca ser un llamado de atención a esta intelectualidad mapuche a no estancarse en aspectos de planificación de corpus que no son los que resultan más relevantes para la situación actual de esta lengua: como se ha venido demostrando en el desarrollo del artículo, su problema, antes que lingüístico, es social y cultural. En el discurso de Painemal (2007), uno de los lingüistas de origen mapuche con más impacto en la esfera de las políticas lingüísticas, se evidencia que esta preocupación por la escritura trasunta una idea matriz: contar con un alfabeto es lo que falta para entrar a las "grandes ligas" de las lenguas, de las "verdaderas" lenguas, con un marcado sesgo evolucionista tras de sí.

Otro fenómeno que destaca en el discurso de la intelectualidad mapuche sobre su lengua, corresponde al rol que ha jugado la educación y la escuela como su manifestación física y social, en el pasado, presente y futuro de su lengua nativa. Hay coincidencia entre estos actores que la situación del mapudungún se define como de un desplazamiento lingüístico acelerado a favor del castellano, que se ha impuesto como lengua dominadora al ser de prestigio social. En tal desplazamiento se identifica a la escuela como uno de sus principales causantes, entre otras razones, al haber inculcado "actitudes de rechazo" hacia las lenguas indígenas. Sin embargo, hay coincidencia en estos discursos (CONADI, 2005; Lefián, 2006) en algo aparentemente contradictorio: a la vez que se le reconoce como uno de los factores destructores de los circuitos tradicionales de producción y reproducción de la lengua, se reconoce a la escuela también como una de las principales herramientas para recuperarlos y dar vitalidad al mapudungún. Aspecto que se vio reflejado tanto en los resultados de la encuesta aplicada como en las entrevistas, analizadas más adelante, realizadas a los mapuches urbanos. El avance de la cobertura escolar, sumado a otros factores, como la creciente pérdida del rol central que jugaba la mujer en la transmisión de la lengua en la familia, trajo como consecuencia la pérdida de los circuitos tradicionales de reproducción del mapudungún: ni la familia ni la comunidad la enseñan, y la escuela aún no suple tal rol. De aquí se deriva que la casi totalidad de los programas que CONADI ha implementado para revitalizar la lengua mapuche tengan que ver con su enseñanza a las nuevas generaciones y que el discurso de las elites giren en torno a este tópico, dejando de lado la reflexión e intervención en torno a la promoción y legitimación social de su lengua nativa. En la misma línea temática encontramos el planteamiento de Loncón (Zalpikan, No 2 , noviembre de 2009), quien señala que a partir de este diagnóstico emerge con nitidez la solución: multiplicar cursos de lengua, formar educadores de ésta, dotar de más herramientas para la instrucción y aumentar la oferta de enseñanza de mapudungún. En otras palabras, se insiste en poner al centro del debate el tema de la 
enseñanza de la lengua. De hecho, es una de los aspectos que se destaca del convenio 169 y de otros cuerpos legales que han aparecido recientemente sobre el tema. Pareciera ser que cuando se habla de "derechos lingüísticos" no se llega más allá de esto, aunque nadie puede dudar que sea un tema trascendente y estratégico. Sin embargo, en el marco de un grupo de discusión que realizamos en 2010 con 30 alumnos (de entre 15 y 18 años) de origen mapuche del Liceo Erasmo Escala, en la población La Faena de Peñalolén, además de quedar claro que lo único que vinculaba a estos adolescentes, fieles representantes de la masa indígena urbana joven, con su condición de mapuche era la Beca Indígena (beneficio económico por tal calidad), se evidenció que uno de los problemas existentes para que se interesaran en seguir un taller de lengua mapuche era que éste les ocupaba parte de la jornada que era para "descansar" (figuraban como actividades extraprogramáticas): resultaba muy difícil el éxito de una iniciativa como esa (y la baja asistencia a las sesiones del "taller" de mapudungún así lo atestiguaba) porque no estaba incorporada en el currículum, máxime en una jornada escolar completa donde esos contenidos no son considerados como relevantes. Esta situación concreta pone de manifiesto algo que creemos es relevante: que el tema central respecto de la recuperación de la lengua no se puede circunscribir solamente al número de talleres, de profesores o de metodologías de enseñanza, sino que debe abrirse también a incluir la necesidad de espacios institucionales, políticos y sociales, además de acciones en torno a la oficialización del mapudungún y su legitimación social para que los primeros puedan adquirir sentido para los mapuches urbanos.

Otro tópico de interés en el discurso de las elites sobre la lengua corresponde a las coordenadas en torno a las cuales definen tanto el problema de la vitalidad del mapudungún como su solución. Tales ejes emergieron en el "Primer Congreso de Lenguas Indígenas", iniciativa que organizó la RED de derechos lingüísticos indígenas en Chile, realizada el mes de julio de 2010 en la Universidad de Santiago de Chile, en la capital. En tal encuentro se dieron cita diversos representantes de todas las lenguas aborígenes de Chile, incluyendo algunos invitados de comunidades quechua y náhuatl, entre otras. El encuentro fue un espacio privilegiado para conocer los discursos que generan las elites respecto de sus lenguas. Al analizar los ejes conceptuales que definen sus expectativas en torno a la recuperación de la vitalidad de su lengua nativa, encontramos, primero, que se conceptualiza el tema desde una perspectiva cuantitativa: "la vitalidad de las lenguas depende del aumento del número de hablantes" (Zalpikan, No 6, junio de 2010). Además, su solución (vía el aprendizaje de las lenguas) se sitúa en el ámbito de la volición, lo ético y lo aleja de la perspectiva y tratamiento social: “... es una decisión y deber individual” (Zalpikan, No 6, junio de 2010). Este carácter ético del llamado a los mapuches urbanos a recuperar su lengua es lo que contrasta con la visión oficial que apuesta a la libre elección del mapuche en cuanto a definir su rol en la sociedad: integrarse o seguir anclado en su condición, la que iguala a pobreza. Por otra 
parte, el carácter individual de la recuperación y su motivación se retroalimenta al asociarse a la racionalidad con arreglo a fines propio del mundo occidental, dado que conocer sus lenguas nativas "... les proporciona horizontes culturales más amplios, mayor capacidad comunicativa y agilidad mental, entre otras ventajas" (MapuExpress, 16 de julio 2010). Vemos así que hay una legitimización externa -dependiente del criterio de "costo-efectividad"- para la decisión de ser o no bilingües. Finalmente, Elisa Loncón, una de las principales gestoras del encuentro, defiende la recuperación de la lengua afirmando que es un "derecho humano fundamental" (Zalpikan, No 2, noviembre 2009), con lo que plantea la posibilidad de observar el tema desde una perspectiva universal, ética, judicial, pero recurriendo a una legitimidad ajena (una especie de ad mapu de otra racionalidad). Hay aquí, al parecer, una contradicción entre un discurso "particularista" (que rescata la necesidad de reconocerse desde su carácter único y original, transversal a todo discurso indigenista) y este enfoque "universalista" de la reivindicación lingüística mapuche. En suma, se trata de un discurso que pugna entre una visión más particularista, ética y colectiva de la reivindicación de la lengua y otra que se construye desde las coordenadas propias de la racionalidad occidental ajena: individual, volitiva y justificada desde el universalismo y el derecho.

\subsubsection{La representación de los hablantes}

\subsubsection{El rol del mapudungún}

Si nos guiáramos por el universo conceptual de la relación "lengua-cultura" propuesto por Salas (1985) para el mapudungún, que señalaba que "hablar en mapuche es vivir en mapuche', la mayor parte de nuestros encuestados y entrevistados habrían dejado de ser socioculturalmente mapuches, al castellanizarse en la ciudad y asumir modos de vida que se asimilan al resto de la población chilena (Wittig, 2009). Lo mismo ocurre si consideramos las nefastas consecuencias que, a nivel individual, identificaban algunos intelectuales mapuches fruto de la pérdida de la lengua nativa (Painemal, 2007). Sin embargo, los discursos nativos que recogimos nos muestran algo distinto: sujetos que están estructurando su identidad mapuche urbana desde otras coordenadas, donde, si bien la lengua no es un elemento actualizado como instrumento para la comunicación efectiva, sí está presente como una herramienta simbólica para construir un horizonte de sentido respecto de lo que es ser "mapuche" en la ciudad. Luego, no hablar mapudungún no los excluye de su condición étnica. Sin embargo, aunque este carácter no excluyente de la carencia de competencia en mapudungún para "ser mapuche" tenga una validez general, sobre todo para su relación con la sociedad chilena, ser capaz de hablar su lengua nativa, o hablarla mejor que otros, es algo que sí tiene importancia al momento de definirse dentro de las propias comunidades mapuches urbanas, como "mejor" o 
“más” mapuche que otros (aspecto que profundizaremos más adelante).

Los mapuches urbanos han generado una serie de representaciones sociales en torno a su lengua, en las que, a pesar de que su nivel de competencia sea nulo o muy bajo (tal como lo hemos mostrado en la fase cuantitativa de este estudio), el mapudungún sigue jugando un rol central en su identidad como comunidad, razón por la cual hablar sobre su lengua es también hablar sobre su condición de mapuches urbanos, un nuevo mapuche que tal vez no tenga la apariencia externa de uno tradicional (ni sus rasgos físicos, ni su vestimenta), pero que manifiesta su resistencia hacia los procesos de creciente des-etnificación (aludidos en el análisis del discurso oficial) a través de la valoración y rescate de su lengua. "Mapuche" significa 'gente de la tierra', tierra que se perdió al momento de migrar a la ciudad y convertirse en obreros, productores de materia prima o trabajadores puertas adentro (aseo, jardinería, cocina, etc.). Esta situación, sumada al resurgimiento de la valoración de su condición étnica, ha generado la necesidad de recurrir a diversos aspectos simbólicos desde los cuales generar su identidad. En tal sentido, resulta interesante constatar cómo sigue apareciendo en sus relatos la tierra como un elemento nuclear en el discurso de la identidad, aunque sea urbana (lo que contradice la tesis des-etnificadora propia del discurso oficial), señalando: “... nosotros creemos en la madre tierra y por eso nosotros sin tierra no somos nada, por eso mismo se justifica la reivindicación mapuche...” (M.P.). Algo similar plantea otro peñi, cuando señala que “... para mí ser mapuche es adorar la tierra, porque yo adoro la tierra; mi lugarcito lo tengo lleno de vida... yo digo vida porque son mis plantas, hasta los gusanos que les entierro las hojitas y se las comen... eso para mí es ser mapuche, tener un lugarcito donde hay vida, en donde yo tiro el agua y sale ese olorcito húmedo, eso es ser mapuche" (L.L.).

Por otra parte, otro recurso simbólico que emerge es la sangre mapuche, un elemento no visible, pero que define profundamente su condición, aun cuando no haya lengua, incluso apellido. Así se desprende de la opinión de una lamngen: “... todo tiene una mezcla, aunque sea un gramo de sangre, ya es mezcla, porque muchas veces no tenemos el apellido, pero la sangre es la que vale, lo que está dentro... porque mucho... 'yo me llamo González González, González Pérez, pero la sangre, puede ser hijo de mapuche que fue reconocido por otra persona y empieza a hacer averiguaciones..." (V.G.). El tópico de la sangre puede llegar incluso a reemplazar a la lengua, como aparece en palabras de otra lamngen, cuando se le pregunta por si, a pesar de que su hija no habla mapuche, de todas maneras podría ser considerada como tal, a lo que responde que “... igual va a ser mapuche... Por la sangre, como dice mi mami” (F.H.). Eso permite que reconozca a su hijos como tales, aunque no hablen la lengua ni lleven las vestimentas típicas. Precisamente, otro aspecto generador de identidad lo encuentran en la vestimenta, tal como una entrevistada que señala que se siente participando más de la cultura mapuche cuando “... me pongo chamal... Cuando voy al campo y pal 12 de octubre me 
lo pongo aquî" (L.P.); o como esta otra, que nos relata, en relación a su hijo, que “... así sería mapuche y hablaría su idioma, y si tiene su ropa, mejor" (M.P.). De hecho, cuando a otra lamngen se le pregunta sobre cómo hacer para mantener su cultura, señala: "... poniéndoles chamales a las chiquillas para que se sientan mapuches, ponerle trarilonko, y a los hombres igual manta, que tengan su cintillo, su moño, todas esas cosas, que toquen instrumento" (F.H.).

Finalmente, es la lengua el elemento nuclear reconocido por los mapuches urbanos para reconocerse a sí mismos y ante sus pares como representante fiel de su comunidad originaria, como lo señala un entrevistado, para quien "... si uno no prefiere hablar en mapuche yo creo que ya no nos sentiríamos mapuches... los mapuches estamos en todas partes... y si no lo habláramos, o sea, uno ve siquiera con la vestimenta se siente hermano... y con mayor razón si hablamos la lengua" (L.M.). La experiencia de una lamngen en un grupo de mujeres mapuches en la comuna de La Pintana reafirma esta percepción: “... porque allá en la ruka cuando hablo en español no más... dicen las tradiciones y yo no me siento en ese lugar... cuando hablan en mapuche yo me siento como que estoy en una reunión de mapuches y siento que si no se habla no es igual" (F.J.). Es en su participación en el espacio donde la lengua refuerza su rol identitario, acicate para conocerla, por tanto, en palabras de otro peñi: “... los nguillatunes, que son la ceremonia religiosa más importante... todo se habla en ese idioma, tú te comunicas con las fuerzas que hay en el mundo con ese idioma... entonces es algo súper importante, si tú quieres pedirle... a Ngenechén, que es el dios, y tú no se lo puedes hacer en español... Tienes que hablarlo en el idioma nuestro..." (M.P.). En el contexto ritual, entonces, la carencia de la lengua emerge como algo que trasciende lo comunicativo, según se infiere de los discursos registrados: “... siento que cuando estoy ahí me falta algo... cuando la machi habla en mapudungún, y la gente empieza a hablar en mapudungún, y tú no entiendes lo que te están pidiendo, no entiendes lo que te están hablando, entonces yo siento que algo me falta, como para poder ser lo que soy...” (M.R.). Más, aún, las propiedades de la lengua en su función identitaria van más allá: “... todo se hace en ese idioma, en el fondo tú te puedes comunicar con la tierra, con las fuerzas, con el aire, con todo... pedirle al agua... y si no... como que igual no tiene... mucha validez...” (M.P.). Así, la lengua se suma como recurso simbólico, conformador de la identidad mapuche, a otros elementos, como la tierra, la sangre o las vestimentas, pero con un carácter fundamental.

Además, el mapudungún, y su recuperación por parte de los mapuches urbanos, adquiere mayor relevancia al ser concebido como la posibilidad de volver a comunicarse con su comunidad origen, el sur; ese sur construido simbólicamente como un espacio de preservación de lo mapuche en sus manifestaciones más originales y 'puras'. Así se evidencia en el discurso de esta lamngen: “... para mi papá es rememorar todo lo que fue su infancia, porque, en el fondo, a él le enseñó a 
hablar su abuelo, y él habla mapudungún con la gente cuando está en el sur, o sea, para él es hacer un retroceso en la vida y llegar a lo que fue su infancia..." (C.S.). También este espacio simbólico original se recuerda y construye como espacio de su socialización como mapuche, en otras palabras, un lugar donde se aprende a ser mapuche: "... en esos viajes que nos hacían al sur, en el que compartíamos con mi abuela, nos empapábamos de todo eso, de esas vivencias del sur, las costumbres de la tortilla, del mudai, del catuto, del estar comiendo todas esas comidas típicas del mapuche, fue algo demasiado natural...” (M.P.). De hecho, otro entrevistado describe como, ya pasados varios años aquí en Santiago, experimenta una sensación de extrañamiento al enfrentarse a esa comunidad originaria: “... si bien yo he ido para el sur, cuando era chica po', cuando uno viaja con los papás y todo, pero después ya mi destino no siguió... Es parte mi papá y mi mamá de esa comunidad, yo no me siento parte, porque en el fondo nunca he convivido nada más que cuando era chica allá po', yo llegar allá me siento como una extraña po" (C.V.).

\subsubsection{Razones del desplazamiento funcional/ Claves para la revitalización}

Las razones de la situación de desplazamiento funcional del mapudungún están nítidamente expresadas en la representación social de los mapuches urbanos. Todos los relatos sobre la pérdida de la vitalidad de su lengua nativa apuntan a la convergencia de múltiples factores en torno a un fenómeno central y articulador: la pérdida y ruptura de los circuitos tradicionales de producción y reproducción de la lengua mapuche. Este fenómeno se habría provocado en virtud de a) la pérdida de la comunidad tradicional y, con ello, de redes sociales efectivas en las que la lengua se produzca y reproduzca; b) la pérdida de la familia como espacio para aquella función; y c) la pérdida del control cultural sobre la lengua como bien simbólico.

La pérdida de la familia como espacio de reproducción de la lengua se ve reflejada en un caso que resulta paradigmático: ella, una machi, y su marido eran monolingües en mapudungún en su comunidad de origen. Llegaron a Santiago y mantuvieron la lengua entre ambos, sin embargo ninguno de sus hijos la habla, debido a que la familia -su familia- dejó de ser espacio de reproducción: “... conversábamos porque igual era indígena el finado de mi marido, porque falleció después, falleció aquí. Y hablábamos los dos, menos los hijos, no saben, porque los hijos no, no saben hablar el idioma como hablo yo, porque ellos nacieron aquí también, los demás (que) traje de allá chicos, tampoco (hablan), olvidaron... ahora hablan puro chilenazo (castellano)... cuando nacen aquí no saben hablar. Igual sabían hablar y perdieron todo" (V.G., paréntesis nuestros).

Entre los factores que han llevado a esta situación encontramos a la experiencia de discriminación, o la expectativa de ella, en la ciudad (sobre todo en la escuela). Esta discriminación, a su vez, se encuentra muy asociada a la pérdida de redes sociales, factor que extiende los problemas de reproducción de la lengua a nivel de 
la comunidad, al impedirle tener espacios donde reproducir su lengua, algo que no sucedía en la comunidad de origen -ya sea como realidad o como construcción discursiva. Otro factor incidente es la pérdida de las rutinas tradicionales en la comunidad originaria, en las que sí era posible la reproducción de la lengua: actividades, tiempos, distancias que no se prestaban a otra cosa que a conversar con sus pares, tal como recuerda una lamngen entrevistada: "Sí y después también, porque yo tenía unas primas que íbamos a buscar frutas al cerro, dihueñes, todas esas cosas y ahí hablamos todo el camino, todo el cerro y nos veníamos conversando y a veces ellas sabían más que mí, sí. Sí, entonces yo le enseñaba a ella o ella me enseñaba a mí, hablábamos fuerte, fuerte... antes de entrar al colegio era puro mapudungún... dice mi mami" (F.H.). Otra actividad tradicional que se ve truncada por las dinámicas de la vida actual en la ciudad, en donde el tiempo no abunda y la lógica apunta a su maximización, con largas jornadas laborales y tiempos de viaje hacia y desde los trabajos, es el "tomar mate", instancia fundamental para el intercambio de experiencias y circulación de la lengua. Sólo recuperado, en términos masivos, en el seno de agrupaciones indígenas, pero no siempre en la familia. Finalmente, se agrega también, y en cierta medida como consecuencia de lo anterior, la pérdida del control cultural que tienen los mapuches sobre un bien cultural como su lengua. Al estar insertos en una sociedad dominadora, sus prácticas no son capaces de reproducirse de modo autónomo. Es así que los trámites no se hacen en su lengua y los medios masivos de comunicación no son en mapudungún; las transacciones económicas tampoco lo son, etc. Sin embargo, en este punto, se debe recalcar el rol que juegan las organizaciones sociales mapuches de diversa índole en la recuperación de estas redes sociales, tal como lo señalaba una entrevistada, refiriéndose a su participación en una agrupación mapuche de mujeres en la comuna de La Pintana, en donde ellas reproducen actividades tan tradicionales como el telar, instancia en la que aprovechan de realizar intercambios en lengua mapuche.

Otro factor incidiendo en esta ruptura de los circuitos tradicionales de enseñanza-aprendizaje del mapudungún corresponde a la carencia de funcionalidad de la lengua en la sociedad, lo que repercute también en el bajo estímulo para su aprendizaje y su enseñanza, tal como lo afirma otra entrevistada: “... ¿а una persona común y corriente, de qué le sirve saber mapudungún?, no le sirve de nada, si tú un idioma lo sabes y no lo practicas, se pierde..." (D.H.). Por un lado es eso, y por otro lado está el hecho de que el medio ambiente externo no lo hace necesario: “... aun cuando yo lo haya aprendido cuando chica, no sé po, si el mundo me está pidiendo saber inglés, y no tengo con quién practicar el idioma, porque no sé po, mi hermano no lo sabe, y... te casas y tu marido no lo sabe... tus compañeros de trabajo tampoco lo saben..." (M.P.). Y agrega respecto de la condicionante del medio ambiente externo, al decir, en relación a su actual intención de aprender mapuche: “... no es como una prioridad que tenga ahora, quizás mi prioridad sería aprender inglés, porque el medio te lo pide, el trabajo te lo pide...” (M.P.). 
Es decir, es capaz de identificar que si no se avanza en la promoción social, nada se obtiene con sofisticar las estrategias y espacios de aprendizaje (que es la tendencia desde el discurso de la elite intelectual mapuche). De esta manera, la falta de contexto también es un factor que ha cortado los circuitos de transmisión tradicional en las familias.

En un nivel más microestructural, en la misma familia, aun existiendo hablantes competentes, no resulta posible que se utilice cotidianamente la lengua nativa con fines prácticos, situación que ocurre en la comunicación entre las nuevas y antiguas generaciones, constituyendo un motivo de desincentivo de uso para las segundas y carencia de estímulo de aprendizaje para las primeras. Se instaura así el bloqueo de la circulación de la lengua en su medio ambiente natural por excelencia. Así lo señalan los entrevistados: “... cuando mi mamá sabía hablaba harto, pero con el tiempo se le ha ido olvidando, donde va perdiendo la práctica... Sí po’, lo van perdiendo po', hasta mi abuela po', como nadie le entiende de los nietos" (D.H.). Existe entonces un efecto paradójico de que la baja competencia de las nuevas generaciones hace que las antiguas aprendan castellano y tengan menos incentivo para usar mapuche en sus casas, generándose un círculo vicioso. Es el caso, también, narrado por un hombre joven, segunda generación de llegados a Santiago, que nos contaba cómo su abuelo, anteriormente monolingüe en mapudungún, se ha visto obligado poco a poco a dejar su lengua en pos del castellano por constricciones dentro de su propio grupo familiar.

Adicionalmente, otro factor de nivel micro que termina bloqueando los circuitos tradicionales de reproducción de la lengua está dado por cómo las pautas de conducta propias de la construcción de género tradicional mapuche se han visto afectadas por las dinámicas de funcionamiento de la mujer en la sociedad compleja actual, en particular, en un contexto urbano pauperizado, característico de los grupos mapuches en la urbe, afectando con ello el papel que la mujer tiene en la socialización lingüística de sus hijos. En la sociedad tradicional mapuche le correspondía a la mujer un rol central en la reproducción de la cultura y, en particular, de la lengua en la familia nuclear. En el fogón, en la cocina, espacio central de socialización de las familias mapuches, la mujer exponía a los hijos a la lengua. En la ciudad, en la medida que ella se incorpora a las estructuras de expectativas que orientan su rol de género, éstas la obligan a salir del hogar para incorporarse al mercado laboral, impidiéndole ejercer a cabalidad como figura catalizadora de la lengua y la cultura en la casa. Estos factores hacen que la familia deje de ser un espacio de reproducción, dada la baja competencia que logran sus integrantes, por lo que no se habla mapudungún en su seno: la mujer, inserta en las dinámicas del mundo laboral (como nana, obrera, etc.), es expulsada del hogar y pierde, en muchos casos, su rol central en la transmisión de la lengua.

En cuanto a las claves para la revitalización de su lengua nativa, los mapuches urbanos, al igual como quedaba en evidencia en los resultados de la encuesta apli- 
cada y en los discursos de las 'élites' sobre su lengua, junto con el reconocimiento del rol negativo de la escuela en el desplazamiento funcional del mapudungún, y su consecuente pérdida de vitalidad, proyectan a la escuela como un espacio de socialización en la lengua, tal vez el espacio por excelencia tras la retirada de la familia con tal función. Ha pasado a formar parte de sus expectativas el que la enseñanza-aprendizaje del mapudungún deje su contexto natural de ocurrencia la familia, la comunidad- para desarrollarse en uno más "artificial", propio de una lógica cultural -occidental- que le es ajena, que puede ser tanto la escuela como los talleres de lengua. Trasladan, de este modo, la enseñanza del mapudungún a espacios no tradicionales y "artificiales" (entiéndase, no naturales) de reproducción.

\section{CONCLUSIONES}

Frente al escenario de retroceso funcional del mapudungún (un dato objetivo que hemos constatado), el análisis cualitativo nos entrega nuevos derroteros a seguir, relacionados con la representación social que en torno a su lengua han construido los mapuches urbanos. Primero, si bien no existen incentivos instrumentales para aprenderla, se la sigue considerando un elemento nuclear en la definición de lo que significa ser mapuche en la actualidad. Se reconoce así su valor simbólico, identitario, antes que lingüístico, en tanto instrumento para comunicarse. De esta manera, la actitud positiva que exhiben ante el mapudungún tiene que ver con su valoración de una de las dimensiones de la lengua en tanto objeto actitudinal: ya no como instrumento de comunicación eficaz, en donde carece de prestigio, sino que más bien como marca de identidad, en donde sí lo posee, y cada día con mayor fuerza en el marco de los procesos de reetnificación en la ciudad (Gissi, 2004a, 2004b; Zúñiga 2007). En segundo término, si bien se han bloqueado los circuitos tradicionales de uso y reproducción de la lengua (la familia, la comunidad), se empiezan a legitimar nuevos espacios -como son los talleres urbanos para aprender la lengua- y espacios más formales -como la escuela (y sus programas de EIB, que deberían adquirir mayor relevancia), ello como una respuesta también ante el debilitamiento de las agrupaciones mapuches. El nuevo rol de agencias de socialización en la lengua como la escuela o talleres informales es también fuente de un cambio en las dinámicas sociales de la lengua mapuche en el espacio urbano, lo que se traduce en una inversión del eje societario (Lagos, 2006) como factor explicativo del posicionamiento de los mapuches frente a su lengua y cultura. Tradicionalmente, se asociaba mayores niveles de competencia a una edad mayor. Sin embargo, en la medida que el aprendizaje y reproducción de la lengua salen del hogar y la familia para concentrarse en otras agencias secundarias, "artificiales", son las nuevas generaciones, en la medida en que acceden a estas agencias y sus lógicas racional-iluministas - no mapuches, por tanto- quienes poco a poco van a 
lograr exhibir niveles de competencia más acabados. De esta forma, el sujeto que se haya expuesto más a ellas, va a conocer y valorar más su lengua. Se da entonces la aparente paradoja de que es la racionalidad del conquistador (o invasor, según sea la óptica), aquella racional-iluminista, la que parecería entregar la clave para rescatar un elemento cultural como la lengua sobre el cual los mapuches perdieron el control cultural. Finalmente, esta posible revitalización aparece como utópica, toda vez que nos centramos sólo en los aspectos de la producción (es decir, que se vuelva a aprender a hablar mapuche). Estos nuevos espacios tienen la desventaja (frente a la familia y la comunidad) de que si su actividad no se acompaña con la generación de espacios de uso (los que eran connaturales a los espacios tradicionales de aprendizaje previos, tradicionales) y legitimación, condenan a esa reproducción y producción al fracaso, a la ineficacia. La teoría y los datos obtenidos demuestran que es necesario que, desde afuera, se le otorgue espacios de funcionalidad que legitimen el conocimiento de la lengua, en lo que se refiere a sus condiciones de reproducción. Y eso es una tarea que le corresponde no sólo a los mapuches, sino que requiere generar interfases y diálogos con la sociedad chilena en su generalidad. Por tanto, requiere que, así como Lautaro supo utilizar un elemento cultural que le era ajeno -el caballo- para elaborar algún grado de resistencia frente al invasor peninsular, los mapuches actuales, aglutinados en sus diversas agrupaciones interesadas en revitalizar la lengua, sepan utilizar las estrategias de planificación y promoción social de la lengua que la sociedad no mapuche, wingka, ha generado. Sin embargo, a la vez, esa sociedad no mapuche debe hacerse más receptiva a una integración intercultural, y no sólo multicultural, con el mundo mapuche, capaz de dialogar y aceptar la diferencia. Algo que históricamente no ha hecho.

\section{REFERENCIAS}

CEP. 2006. "Estudio de opinión pública. Los mapuche rurales y urbanos hoy" [en línea]. Disponible en http://cepchile.cl . Consulta: 15/09/2009.

Chiodi, Francesco y Elisa Loncón. 1995. Por una nueva politica del lenguaje. Temuco: Pehuén.

CONADI. 2005. Primer Seminario Taller: Experiencias y conocimientos para el fortalecimiento y la promoción de las lenguas originarias. Santiago de Chile: MIDEPLAN - CONADI.

Croese, Robert. 1983. "Algunos resultados de un trabajo de campo sobre las actitudes de los mapuches frente a su lengua materna", en RLA 21, pp. 23-34.

Fernández, Isabel y Arturo Hernández. 1981. "Estudio exploratorio de actitudes en una situación de bilingüismo: el caso mapuche", en RLA 22, pp. 35-51.

Gissi, N. 2004a. "Segregación espacial mapuche en la ciudad: ¿negación o revitalización identitaria?” [en línea]. Disponible en http://revistaurbanismo.uchile. 
cl. Consulta: 03/08/2009.

Gissi, N. 2004b. "Los mapuche en el Santiago del siglo XXI: desde la ciudadanía política a la demanda por el reconocimiento" [en línea]. Disponible en http:// cultura-urbana.cl. Consulta 03/08/2009.

Gunderman, Hans, Jaqueline Canihuán, Alejandro Clavería y César Faúndez. 2009. "Permanencia y desplazamiento, hipótesis acerca de la vitalidad del mapuzugun”, en RLA 47 (1), pp. 37-60.

Hasler, Felipe, Cristián Lagos, Héctor Mariano, Daniela Molina y Cristián Oyarzo. 2009. ¿Mongeley kam mongelelay chi mapudungun waria mew? Vitalidad y representación social del Mapudungún en Santiago de Chile. XVIII Congreso de la Sociedad Chilena de Lingüística. Santiago de Chile: Chile.

Hernández, Arturo. 1983. "Situación sociolingüística de una familia mapuche: proyecciones para abordar el problema de la enseñanza del castellano", en $R L A$ 21, pp. 35-44.

Hernández, Arturo y Nelly Ramos. 1978. "Rasgos del castellano hablado por escolares rurales mapuches. Estudio de caso", en RLA 16, pp. 141-150.

. 1979. "Estado actual de la enseñanza del castellano a escolares del área rural: un problema de bilingüismo y lenguas en contacto", en Estudios Filológicos 14, pp. 113-127.

Hymes, Dell. 1971. "La sociolingüística y la etnografía del habla”. En Ardener, Edward (Ed.). Antropología Social y Lenguaje. Madrid: Gredos, pp. 115-152.

INE. 2002. Censo 2002. Síntesis de resultados [en línea]. Disponible en http:// ine.cl. Consulta: 10/09/2009.

Instituto Libertad y Desarrollo (ILD). Serie Documentos Públicos [en línea]. Disponible en http://www.LYD.org. Consulta: 29/08/2010.

Lagos, Cristián. 2006. "Mapudungún en Santiago de Chile: vitalidad, lealtad y actitudes lingüísticas", en Lenguas Modernas 31, pp. 97-126.

Larroulet, Cristián. 2009. "Conflicto mapuche y políticas públicas", en Diario El Mercurio, 10 de enero.

Lefián, Manuel. 2006. Recuperación y revitalización de las lenguas indígenas. Serie Documentos Técnicos No 1. Santiago de Chile: CONADI - MIDEPLAN.

MapuExpress (periódico electrónico) [en línea]. Disponible en http://www.mapuexpress.net/. Consulta: 17/11/2010.

Mariano, H. 2009. Consenso sobre el uso del alfabeto mapuche. Santiago de Chile: Comisión Lingüística Mapuche Metropolitana.

Molina, Daniela, Felipe Hasler, Cristián Lagos, Héctor Mariano y Cristián Oyarzo. 2009. "Perfil etno y sociolingüístico del Mapudungún en Santiago de Chile", en Lenguas Modernas 34, pp. 25-51.

Munizaga, Carlos. 1961. Estructuras transicionales en la migración de los araucanos de hoy a la ciudad de Santiago de Chile. Santiago de Chile: Editorial Universitaria. 
Oyarzo, Cristián, Felipe Hasler, Cristián Lagos, Héctor Mariano y Daniela Molina. 2010. "¿Mongeley kam mongelelay chi mapudungun waria mew? Vitalidad y representación social del mapudungún en Santiago de Chile”, en Romanitas, Lenguas y Literaturas Romances 4 (2), pp. 42-69.

Painemal, Martín. 2007. Acerca de las lenguas indígenas en el país. Santiago de Chile: Documento técnico CONADI.

Salas, Adalberto. 1985. "Hablar en mapudungún es vivir en mapuche. Especificidad de la relación lengua-cultura", en RLA 25, pp. 27-35.

Von Baer, Enna. "La cuestión mapuche: raíces, situación actual y desafíos futuros" [en línea]. Disponible en http://www.lyd.com/noticias/cuestion_mapuche. html. Consulta: 25/09/2010.

Wittig, Fernando. 2009. "Desplazamiento y vigencia del mapudungún en Chile: un análisis desde el discurso reflexivo de los hablantes urbanos", en $R L A 47$, pp. 135-155.

Zalpikan, Suplemento de diario "Azkintuwe" [en línea]. Disponible en http:// www.azkintuwe.org/publicaciones.htm. Consulta: 30/10/2010.

Zúñiga, F. 2007. "Mapudunguwelaymi am? '¿Acaso ya no hablas mapudungún?' Acerca del estado actual de la lengua mapuche”, en Estudios Públicos 105, pp. $9-24$. 